\title{
La administración de la justicia eclesiástica en el Río de la Plata s. XVII-XVIII: un horizonte historiográfico*
}

\author{
The management of ecclesiastical justice in Río de la Plata in the $17^{\text {th }}$ and \\ $18^{\text {th }}$ centuries: historiographical horizons
}

\author{
Miriam Moriconi \\ miriammoriconi@hotmail.com \\ Profesora-Investigadora \\ Universidad Nacional de Rosario \\ Entre Ríos, 758 \\ 2000 - Rosario - Santa Fe \\ Argentina
}

\section{Resumen}

El trabajo expone las diferentes formas de tratamiento que ha merecido la justicia eclesiástica ordinaria en la historiografía sobre el Río de la Plata en el período comprendido por los siglos XVII y XVIII. A partir del relevamiento bibliográfico, se comunican algunos trazos historiográficos resultantes de la indagación de los modos en que aparecen mencionadas fuentes de derecho, potestades de personas eclesiásticas y del uso que se ha dado a los documentos generados en la administración de justicia eclesiástica en diferentes ámbitos diocesanos. Se pretende una reflexión crítica orientada al diseño de una propuesta para el estudio de los jueces eclesiásticos y el abordaje de la administración de justicia eclesiástica en el ámbito parroquial.

\section{Palabras clave}

Historiografía; Eclesiología; Argentina.

\begin{abstract}
This paper explains the different forms of treatment that have been dedicated to ordinary ecclesiastical justice in the historiography on Rio de la Plata in the seventeenth and eighteenth centuries. From the literature survey, it communicates some historiographical lines resulting from the investigation of the ways in which the sources of law and the power of the clergy are mentioned, as well as of the use that has been made of the documents generated in the ecclesiastical administration of justice in different dioceses. It intends to make a critical reflection that may lead to the design of a proposal for the study of ecclesiastical judges and an approach for the administration of justice at the parish level.
\end{abstract}

Keywords

Historiography; Ecclesiology; Argentina.

Enviado el: 25/6/2012

Aprobado el: 14/8/2012

\footnotetext{
* El presente trabajo se realiza en el marco del Proyecto de Investigación Plurianual PIP 0318, CONICET, "Relaciones de poder y construcción de liderazgos locales. Gobierno, justicias y milicias en el espacio fronterizo de Buenos Aires y Santa Fe entre 1720 y 1830". Vigencia: 2010-2012. Agradezco la lectura atenta y contribuciones que han hecho de este artículo Darío Barriera, María Elena Barral y Elisa Caselli, así como la de los referís anónimos de esta Revista.
} 
La prédica del clero sobre la sumisión y obediencia a Dios y al Rey ha sido interpretada como baluarte del dominio español en América. Sin embargo, el clero no solamente ha obrado en el plano de la persuasión discursiva con la poderosa arma del púlpito (DI STEFANO 2004), con su potestad divina de salvación de las almas y la administración del sacramento de la penitencia, sino que, además, detentó capacidades jurisdiccionales. Así como otras instancias de gobierno indiano se fundaron en una administración investida de poderes judiciales (GARRIGA 2006), también la administración diocesana cristalizó una forma de gobierno en torno a los tribunales eclesiásticos.

La producción de conocimiento de esa faceta de la historia eclesiástica exhibe un desequilibrio muy pronunciado entre las diferentes regiones del territorio americano cuya nota común es el predominio de los análisis sobre justicia inquisitorial (TRASLOSHEROS 2010a; GUIBOVICH PÉREZ 2003). Recién en las últimas décadas, los historiadores han dirigido la atención al campo menos explorado de los tribunales eclesiásticos ordinarios y una renovación de las perspectivas de análisis procede del cruce de la dimensión institucional y cultural de los mismos.

La mayor parte de los estudios se ha concentrado prioritariamente en la relación de la administración de justicia eclesiástica con los indios (AGUIRRE 2008; TRASLOSHEROS 2010b; LARA CISNEROS 2010). Algunos lograron demostrar el frecuente uso que los indios hicieron de los tribunales eclesiásticos poniendo en cuestión el extendido presupuesto de que los pobladores nativos eran sujetos pasivos perseguidos por la justicia (ZABALLA BEASCOECHEA 2011). No obstante, es obvio que en los tribunales diocesanos indianos no solamente estuvo involucrado el segmento indígena de la población; ya sea como litigantes, reos u oficiales, también lo estuvieron los peninsulares, hispanocriollos, mestizos y castas. Y, como permiten entrever las líneas de investigación iniciadas en la última década, tal vez el aspecto más interesante de la indagación de la práctica judicial sea que en esos ámbitos se tomaban decisiones vinculantes no solo para los actores involucrados directamente en los pleitos, sino también para todo el conjunto social.

La diócesis del Río de la Plata, fundada en el año de 1620 a partir de la segregación de una parte del territorio diocesano de Asunción del Paraguay, estuvo a cargo de autoridades con potestades judiciales eclesiásticas ordinarias que se ocuparon de administrar justicia en sus sedes catedralicias. Además, obispos o provisores en las sedes vacantes, delegaron su potestad judicial en jueces vicarios que se desempeñaron en lugares alejados de la sede diocesana. Estos últimos conocían en los pleitos dentro del término que les era asignado adquiriendo gran relevancia en la vida de las pequeñas comunidades. Las causas más conocidas son las interpuestas por materia de esponsales o nulidad matrimonial (RÍPODAS ARDANAZ 1977; MOLINA 1991; CAULA 2001; GHIRARDI 2003; 2004; LÓPEZ 2008). Sin embargo, sorprende el amplio radio de materias que se dirimieron en esos foros: testimonios de autos obrados por herencia, reclamos por retención o pagos para liberación de esclavos, robos de ganado, joyas y esclavos, verificaciones de parroquialidad, 
desalojos, fianzas y excarcelaciones, certificaciones de bautismo, matrimonio y entierro o huida de esclavos.

Advertida la potencialidad de los archivos judiciales para abordar múltiples aspectos sociales y políticos (FOUCAULT 1996; FARGE 1991), queda por demostrar la importancia que en sí mismo comporta el conocimiento de la administración de la justicia eclesiástica ordinaria, ya que ese es uno de los aspectos menos conocidos del clero colonial.

Actualmente, comienzan a ser mejor conocidas sus fuentes de derecho y han sido indagados los expedientes tramitados en algunas curias diocesanas americanas (DELLAFERRERA 2002; TRASLOSHEROS 2004; FLEITER 2011; MENDONÇA 2011) o aquellos otros en los que el clero tuvo algún tipo de intervención, como son los recursos de fuerza interpuestos en la justicia regia. Pero puede observarse que aún no se ha procedido con el mismo énfasis al estudio de la organización de la justicia eclesiástica en el ámbito parroquial, ni de las formas de reclutamiento, perfil competitivo y prácticas procedimentales de esos jueces.

\section{Los estudios sobre justicia eclesiástica en el Río de la Plata}

Al tratar de diseñar un programa de investigación sobre los referidos tribunales a partir de la bibliografía existente sobre la historia del Río de la Plata bajo el dominio de la monarquía hispánica en cualquiera de sus vertientes historiográficas, sorprende que, hasta hace pocos años, ni los tribunales

212 eclesiásticos ni las formas de administración de dicha justicia ni los propios jueces eclesiásticos, acreditados en una amplia gama de estudios históricos, hayan devenido objeto de análisis. Eso es más sorprendente considerando la emergencia, en las últimas décadas, de líneas de investigación sobre la historia de la justicia trazadas en la encrucijada de la nueva antropología jurídica y la historia crítica del derecho (BARRIERA; DALLA CORTE 2001).

Los avances en este campo en Argentina registran zonas muy sólidas y otras áreas grises o de vacancia (PALACIO; CANDIOTI 2007; CANDIOTI 2009; BARRIERA 2010), una de las cuales es la relativa a la justicia eclesiástica colonial. No solamente no se dispone de estudios medulosos que hayan tratado el tema desde perspectivas analíticas renovadas o a partir de bases teóricas metodológicamente exigentes, sino que tampoco se cuenta con registros analíticos elementales que permitan responder preguntas tales como: ¿Desde cuándo se administró justicia eclesiástica en este territorio? ¿Quién o quiénes designaban a los jueces? ¿Qué perfil debían tener? ¿Quiénes efectivamente desempeñaron el oficio? ¿Durante qué período? ¿Con qué potestades?

Con relación a las fuentes de derecho de la justicia eclesiástica, la historiografía colonial puede abrevar en un valioso legado constituido por un conjunto de trabajos producidos desde la historia del derecho indiano, que, en las últimas décadas, habilitaron articulaciones cada vez más sensibles al abordaje de la historia de un derecho canónico indiano (BRUNO 1967; GARCÍA BELSUNCE 1994; DELLAFERRERA; MARTINI 2002; DELLAFERRERA 2004; 2006; DUVE 2007). En ese segmento, el avance en el conocimiento de desarrollos 
doctrinarios y normativos que exceden el derecho canónico y que regularon el desempeño de los jueces eclesiásticos parece haber alcanzado en gran medida la esfera de los tribunales diocesanos superiores y cualquier indagación acerca de los jueces eclesiásticos parroquiales no podrá realizarse sin el dominio de su conocimiento.

Por otra parte, desde la historia social o la etnohistoria, aunque ni la administración de justicia eclesiástica ni los jueces eclesiásticos hayan constituido su objeto, los desarrollos temáticos de dichas áreas no han podido sustraerse a las actuaciones de esos agentes ni a la documentación por ellos elaborada. En la mayor parte de esos trabajos, mientras se indaga con mayor atención a otros actores sociales, es recurrente la mención de clérigos con potestades judiciales.

Así, en la proyección de un programa de investigación sobre el tema planteado, consideré indagar las perspectivas, los conceptoso categorías analíticas utilizados para el tratamiento de todas aquellas acciones e intervenciones cuyos resultados o efectos conciernen a la calidad de juez eclesiástico, ya sea que los autores en cuestión hayan o no advertido esa condición de los agentes.

Por último, una indagación bibliográfica sobre trabajos más directamente conectados con temas de la historia de la justicia colonial está orientada a examinar el lugar que le cupo a esa otra vara de justicia y a recuperar sus contribuciones para el estudio de la problemática específica planteada.

\section{Visiones y abordajes de la justicia eclesiástica desde la historia del derecho}

Ricardo Levene, uno de los puntales del cambio de valoración del pasado legal colonial que se sitúa en las primeras décadas del siglo XX (DALLA CORTE 1999), reafirmó la necesidad de estudiar la historia del "derecho patrio" argentino demarcando los rasgos particulares del "derecho de Indias". En el segundo tomo de su voluminosa obra Historia del derecho argentino, introdujo la problemática de un Corpus Iuris Indiarum a partir de la incorporación de elementos de múltiples fuentes de derecho -derecho natural, derecho romano, derecho de Castilla- incluyendo acertadamente el derecho canónico. En ese programa, aunque brevemente, pues solo dedicó doce páginas al tema, dio cuenta de la importancia del derecho eclesiástico escapando del corsé de las normas legales e insinuando un clima de jurisprudencia y condiciones materiales precisas en las que pudo desenvolverse la actividad judicial eclesiástica. Se trata de condiciones que actualmente podemos remitir al análisis más aquilatado realizado por Tau Anzoátegui para todo el sistema jurídico indiano (TAU ANZOÁTEGUI 1992), pero que, en verdad, tenían un referente más inmediato. Levene introdujo esa materia a partir de Dalmacio Vélez Sarsfield, autor de Derecho público eclesiástico. Relaciones del Estado con la iglesia en la antigua América española. Publicada en 1871, la obra se inscribía como novedad en un tiempo en el que se esperaba:

que la enseñanza del Derecho Canónico salga del terreno eclesiástico para pasar a ser un estudio de legislación comparada, entre el derecho de la iglesia y el de la sociedad civil: haciendo ver los puntos de contacto que los une, la mutua influencia de uno sobre el otro, el auxilio que 
ambos se prestan y el rol eminentemente civilizador que la legislación eclesiástica ha desempeñado en las modernas sociedades (VÉLEZ SARSFIELD 1871 , p. 11-12). ${ }^{1}$

El protagonista del proceso codificador argentino fue también artífice de esa obra, que, por primera vez, se dedicó a tratar de la relación entre la "Iglesia colonial, el derecho y el Estado". A pesar del álgido debate de sus coetáneos acerca de la utilidad de su contenido y de su trascendencia en la opinión pública, la obra no ha merecido consideración para la historiografía que en este apartado estamos tratando. El libro de Vélez Sarsfield, con la excepción de Abelardo Levaggi, que lo escogió como objeto de su tesis (LEVAGGI 1969), no aparece recurrentemente citado como otras producciones; ni su autor, indefectiblemente vinculado al núcleo intelectual creador del nuevo ordenamiento legal y al proyecto del Código Civil, compone la lista de esa porción del campo académico que se denomina Historia del Derecho Canónico Indiano. Sin embargo, si se presta atención a una advertencia que lanzaba desde el prólogo original, también puede reivindicárselo en ese sentido, ya que, allí, Vélez Sarsfield introdujo la cuña receptiva de dicha fuente de derecho al expresar el punto de partida para su tratado:

Las obras de derecho público eclesiástico escritas para Europa, las leyes mismas con las que se gobiernan aquellas Iglesias, nada pueden enseñarnos porque ninguna semejanza tienen con el derecho Pontificio, ó con el derecho administrativo que ha gobernado las Iglesias de América (VÉLEZ SARSFIELD 1871).

No obstante primar el encapsulamiento de las interpretaciones a un corpus documental que privilegiaba como fuente los corpus legales, su propuesta contempló el aspecto receptivo y amplió el abanico de indagación al resto de producciones jurídicas eclesiásticas aplicadas en América.

En ese sentido, operó el desarrollo de la historiografía del derecho canónico indiano, la cual se nutrió con la incorporación de fuentes producidas a partir de las experiencias americanas, aunque parece haber tenido dificultades para encontrar coordenadas con el resto de la historia del pasado colonial, ya sea en la vertiente de la historia del derecho, como pretendió Vélez Sarsfield, o en la historia política institucional. Siguiendo su curso, el conocimiento de la justicia eclesiástica y sus fuentes jurídicas tuvo base en los aportes realizados por eclesiásticos devenidos historiadores, como lo fueron Cayetano Bruno y Nelson Dellaferrera. Este último, en un análisis que, hasta hoy, en un panorama de estudios sobre los tribunales diocesanos rioplatenses resulta casi excepcional, concluyó que para estudiar la justicia eclesiástica no bastaba leer textos legales ni consultar a los grandes tratadistas de la época, sin indagar las actas procesales (DELLAFERRERA 2002, p. 408). Ese interés y su labor lo convirtieron

\footnotetext{
${ }^{1}$ Carta del Dr. Carlos José Álvarez - catedrático de Derecho Público Eclesiástico en la Universidad de Buenos Aires - al Dr. Luis V. Varela -editor de la obra - en respuesta a su consulta sobre la utilidad de la obra para los estudiantes de Derecho, 28 de julio de 1871.
} 
en protagonista de la consolidación institucional de dicha especialidad dentro del campo de la historia del derecho indiano, ya que fue miembro fundador del Instituto de Historia del Derecho Canónico Indiano, erigido en el año de 2006 en la Facultad de Derecho Canónico de la Pontificia Universidad Católica Argentina en Buenos Aires. Otros miembros de ese Instituto, partícipes de una red de relaciones interdisciplinares e interinstitucionales, ${ }^{2}$ han consolidado espacios para la investigación histórico-jurídica en esa área, ${ }^{3}$ dinamizando, así, el estado del respectivo campo de estudios.

A esa labor puede adjudicarse la recuperación y puesta en valor de normativa local - constituciones sinodales, decretos conciliares, reglas consuetas - (ARANCIABIA; DELLAFERRERA 1979; MARTÍNEZ DE SÁNCHEZ 2003; PEÑA 2003) que propiciaron la ampliación de la base documental considerada de importancia para la historia del derecho canónico indiano. Su divulgación comienza a estimular nuevos enfoques y articulaciones con otras áreas de investigación que auspician un conocimiento más integral sobre las culturas jurídicas y la administración de justicia del período estudiado.

En esta senda pueden reivindicarse aquellos análisis que, aunque se concentren en otros espacios americanos, más que en la letra de la norma han puesto el foco en el hacerse de las normativas, en los modos de apropiación, ajustes o innovación respecto de fuentes jurídicas europeas (Concilio de Trento, concilios peninsulares como el de Granada o Toledo); en la aparición de disposiciones normativas acerca de determinadas materias comunes a las preocupaciones jurídicas y judiciales europeas en las cuales el componte indio o mestizo de la población americana o incluso la misma población negra esclava se presentaban como novedades (DELLAFERRERA 2008; DUVE 2011; DANWERTH 2010). Así, por ejemplo, se han explorado el estatus jurídico de misserabilis personae (DUVE 2007) y la práctica de la administración de sacramentos (MARTINI 1995), lo que resultó en un material de base de consulta obligada al tiempo de analizar la adscripción social de los litigantes en los foros, los procedimientos judiciales o los laberínticos desarrollos de las causas.

\section{La justicia eclesiástica desde la historia social y la etnohistoria}

La indagación acerca de las formas del disciplinamiento social, de las moralidades e imaginarios religiosos acerca de la salud y la curación, así como los desarrollos analíticos sobre el parentesco, el mestizaje y otras temáticas comunes al campo de la historia de la familia, la historia de las mujeres o de la etnohistoria se han realizado basados en documentos elaborados por jueces eclesiásticos; sin embargo, no siempre ha sido advertida o indagada esa condición de la fuente.

\footnotetext{
2 En el ámbito nacional, el Instituto de Historia del Derecho de Buenos Aires. Además, los distintos institutos europeos de Historia del Derecho y el Colegio de Michoacán, Facultad de Derecho de la UNAM (México). Merece citarse particularmente el Instituto Max-Panck de Historia del Derecho Europeo (Frankfurt - Alemania), que, desde el año de 2011, desarrolla una nueva línea de investigación sobre la historia del derecho canónico en América.

${ }^{3}$ Valgan como ejemplo las mesas sobre el tema que ocurrieron dentro de la organización de las sucesivas sesiones del Congreso Internacional de Derecho Indiano y las más recientes del Seminario Internacional "Nuevos campos de investigación en la historia de las instituciones eclesiásticas y del derecho canónico indiano", celebrado en 2011 en México y en 2012 en Lima.
} 
Ya sea cuando se apuntó al análisis de la relación entre valores sobre el matrimonio y la sexualidad (LAVRIN 1982; SUÁREZ 1993), o cuando se buscó establecer una tipificación de delitos y pecados examinando las modalidades de persecución, condena y castigo dirigidos a modelar determinadas prácticas sociales vinculadas a la problemática de la conyugalidad y el comportamiento femenino (ASPELL 2006a; VASSALLO 2006), los investigadores no escaparon de los registros parroquiales, de los expedientes eclesiásticos, ni de la consideración de la matriz católica en la cual el matrimonio es un sacramento esencial de la vida cristiana. Sin embargo, antes que en los procedimientos y configuraciones judiciales eclesiásticas necesarios para la constitución familiar y la inserción social en una comunidad cristiana, esos historiadores se han concentrado preferentemente en la condición punitiva y performativa de los discursos e intervención de los agentes eclesiásticos (MALLO 1992; 2004; DELLAFERRERA 1991; GHIRARDI 2004; 2005; FERREYRA 2005; KLUGER 2005; ASPELL 2006a).

Los jueces eclesiásticos tenían potestad para tomar las amonestaciones pertinentes al otorgamiento de licencias de matrimonio, incluida una función de vital importancia: la de certificar la condición socioétnica de los contrayentes o la de cualquier parroquiano o parroquiana que la requiriera. En una sociedad estamental y pigmentocrática como la colonial (LAVALLÉ 1999; ARES QUEIJA 1997), no debe soslayarse esa poderosa herramienta en sus manos; pues, si bien los jueces eclesiásticos debían ajustarse al derecho canónico, en el término parroquial, determinaban quiénes eran feligreses y quiénes no lo eran, quiénes 216 eran españoles, negros o indios y quiénes eran mestizos, pardos, zambos o mulatos; quiénes eran hábiles para contraer bautismo y matrimonio y quiénes no (MORICONI 2011).

En un estudio acerca de las relaciones entre la descendencia legítima y la bastardía, Roxana Boixadós reconstruyó un caso de efectiva incorporación de hijos ilegítimos mestizos a la sociedad hispanocriolla por medio de la relación con una rama legítima de una familia reconocida en la ciudad de La Rioja. La autora suscribe tangencialmente la implicancia de los agentes judiciales en las tramas sociopolíticas, ya que también advirtió algunas complicaciones experimentadas por uno de los miembros de dicha familia que "tenía cuentas pendientes con la justicia eclesiástica y capitular; entre ellas una excomunión que pesaba sobre él por haber agredido de palabra y acción (violencia manifiesta) al cura vicario y juez eclesiástico del valle de Famatina" (BOIXADÓs 2005, p. 107).

Otros dos ejemplos que, desde concepciones divergentes, se han detenido en una reflexión crítica acerca de la intervención de los jueces eclesiásticos son los aportados por María Elena Barral y Elsa Caula. Barral ha apreciado que "a través de este tipo de mediaciones se convirtieron en piezas clave del funcionamiento burocrático de la monarquía y de su sostén ideológico" (BARRAL 2007, p. 15). Caula, analizando un caso de disenso matrimonial, aunque interpretó a los oficiales de justicia regia como "autoridades judiciales estatales" $y$, consecuentemente, escindidos y diferenciados de las "autoridades eclesiásticas", alertó sobre la incidencia que las redes vinculares entre jueces y pleiteantes podían tener en ese tipo de determinaciones (CAULA 2001, p. 131-132). 
Esas decisiones de peso en las tramas familiares y sociales por parte de quienes, por su estado clerical y, en la mayor parte de las veces, por su pertenencia familiar, eran miembros de las élites locales no debieron pasar por alto a quienes pretendían mover los resortes políticos de la comunidad. La reconstrucción de las políticas matrimoniales para explicar la constitución de las élites no debería omitir el rol de los jueces eclesiásticos. Los registros de licencias matrimoniales, así como las dispensas, además de reservorio de datos, pueden indagarse como dispositivos utilizados por dichos agentes, que fueron mediadores imprescindibles para la concreción de las referidas políticas matrimoniales y para dirimir posiciones en las competencias intra o inter elites.

En otra línea de trabajos que exploran las formas de persecución y castigo de las prácticas de brujería, hechicería o adivinación, se ofrece un conocimiento de los procesos inquisitoriales mucho más exhaustivo si se lo compara con las informaciones disponibles sobre los procedimientos y los recursos de la justicia eclesiástica ordinaria (FOGELMAN 2006; ASPELL 2006b; 2007). La comprensión cada vez más sensible a las singularidades de esos procederes permite realizar relaciones más ajustadas en los complejos ámbitos judiciales, tal como lo ha demostrado Judith Farberman al reconocer la apropiación de los métodos inquisitoriales del Santo Oficio de parte de los alcaldes ordinarios del cabildo de Santiago del Estero, quienes, basándose en unos "rudimentarios" conocimientos de derecho y demonología católica, juzgaron prácticas de hechicería como delitos gravosos contra la fe (FARBERMAN 2005).

De ese modo, orientados hacia otras temáticas, en el horizonte trazado por diferentes intereses, los trabajos referidos abren sendas propicias para indagar a la justicia eclesiástica ordinaria. Lo que asoma de esas lecturas es que, dentro de las reglas del juego del campo de la justicia local, había un amplio margen de maniobra y que esas condiciones también deben haber atravesado a los jueces eclesiásticos. Los miembros de las instituciones eclesiásticas, antes que estar ajenos a los antagonismos de su medio social, estaban permeados por ellos y su condición clerical no es óbice para excluirlos de la consideración de proyectos, estrategias y motivaciones de otros actores que se realizaban en otros ámbitos con proyecciones en un espacio a veces mucho más vasto que la escena local (MOUTOUKIAS 2002, p. 81). ${ }^{4}$

\section{La historia social de la administración de la justicia}

La dificultad de partida para comprender la significación histórica de la justicia eclesiástica deviene de las exiguas e incorrectas interpretaciones de lo que dicha justicia implicaba en el universo heterojurisdiccional del Antiguo Régimen. Son innumerables las aserciones acerca de la condición disciplinaria y punitiva de las instituciones eclesiásticas que confunden la cualidad disuasiva de los discursos eclesiásticos y la administración del sacramento de la penitencia con la justicia penal eclesiástica. Consecuentemente, son muy pocos los estudios que pueden trazar claramente la diferencia entre el factor sacramental de la

\footnotetext{
${ }^{4}$ Ver la aplicación de esta perspectiva a un caso concreto en BARRIERA 2010.
} 
administración del perdón, la administración legal de las penas canónicas, entre las cuales la más mencionada es la excomunión, y las acciones penales devenidas de las sentencias de esos tribunales eclesiásticos. Ha sido recurrentemente citada la advertencia de Bartolomé Clavero en cuanto a las comunidades del Antiguo Régimen en el sentido de que:

Lo que no hay es una religión por una parte respecto a la que se definan los pecados y un derecho por otra en cuya relación se determinen los delitos. Tampoco existe una potestad eclesiástica de un lado estableciendo los pecados y una política de otro haciendo lo propio con los delitos (CLAVERO 1990, p. 65).

Pero, como surge de la mayor parte de la bibliografía consultada, esa indeterminación parece haberse trasladado a las explicaciones acerca de las potestades jurisdiccionales y la composición de ese escenario judicial no quedó tan clara como, por ejemplo, en la exposición de Andrés-Gallego. En efecto, el autor expresó perfectamente, y de un modo que en la historiografía americanista sobre el Río de la Plata es difícil hallar, que "aparte de la justicia civil, estaba la de la Inquisición, híbrida de Iglesia y Corona [...]. Y, aparte, estaba la jurisdicción propiamente eclesiástica" (ANDRÉS-GALLEGO 2000, p. 152).

Juan Carlos Garavaglia se ha referido al poder eclesiástico para describir la trama de poder desde un pueblo de la campaña bonaerense, admitiendo que "con frecuencia, alcaldes de la hermandad y párroco actuaban de consuno" 218 (GARAVAGLIA 2009, p. 168). Sin embargo, omitió precisiones acerca de si el rol fundamental de los curas en la comunidad de Areco solo se debía a las tareas anexas a su ministerio o si, además, esa mirada vigilante del párroco estaba ligada al ejercicio de sus funciones netamente judiciales en virtud de la acumulación en su persona del oficio de juez eclesiástico.

Es una práctica extendida entre quienes han estudiado la administración de justicia colonial que inicien sus mapeos de las varas de justicia considerando únicamente la justicia real y omitiendo la justicia eclesiástica. Podría adjudicarse esa omisión a aquellas líneas interpretativas desarrolladas bajo el gran paraguas del paradigma estatalista, cuyos presupuestos genealógicos del Estado de derecho condujeron a un abordaje anacrónico de la realidad jurídico-política de los siglos XV-XVIII a partir del cual resulta dificultoso operar analíticamente fuera del binomio Iglesia/Estado. Sin embargo, como demostraremos, eso no siempre es así, ya que dicha omisión atraviesa también estudios basados en los lineamientos de la antropología jurisdiccionalista.

Darío Barriera ha llamado la atención sobre la rigidez y precariedad de los análisis que sólo consideran la normativa y un único oficio a escala local (el alcalde de primer voto) y, consecuentemente, ha incluido en su reflexión las demás varas y justicias administradas en la ciudad. Ha reconocido el "imperio de la Iglesia", "la incardinación entre religión y política" y la raigambre teológica y cristiana de la idea de justicia, pero, aun así, ha omitido el tema de la justicia eclesiástica al punto de interpretar que la expresión de Covarrubias "Ios ministros de justicia" solo refiere a "los ministros de la justicia regia" (BARRIERA 2003, p. 77). 
En su libro sobre la justicia penal en Córdoba, Alejandro Agüero afirma:

con respecto al perfil de las instituciones que ejercieron la jurisdicción ordinaria a lo largo de la época colonial, esta no sería otra que la rotunda afirmación de que el poder de hacer justicia en primera instancia estuvo vinculado, a lo largo de todo el período y de forma casi excluyente, a los vecinos del lugar a través de la institución capitular y de su expresión jurisdiccional: los alcaldes ordinarios (AGÜERO 2008, p. 29).

Puede constatarse que el autor no desconoce la importancia y significado de la religión como "la principal fuente de disciplina social" en el orden de las representaciones, en la estructuración de la vida de la comunidad y en los lenguajes jurídico-normativos, aunque, de hecho, se ciña a la mención de influencias doctrinarias o de tipo ontológico. Asimismo, subrayó el uso del derecho canónico, de los textos bíblicos y de "algunos elementos propios del campo espiritual en el ejercicio de la jurisdicción criminal secular" (AGÜERO 2007), pero ignoró el rol que les cupo a las agencias eclesiásticas y a sus atribuciones jurisdiccionales.

Si bien es cierto que desde esas miradas se ha otorgado un mayor protagonismo a los actores y a las prácticas y se acentuó el interés sobre los usos de la ley y las estrategias diseñadas de parte de legos o letrados, inaugurándose, así, una nueva relación cognitiva entre la política y la justicia durante el Antiguo Régimen, resta incorporar al análisis el segmento eclesiástico del campo judicial.

Adoptando otra perspectiva analítica, Jaqueline Vassallo comunicó, en una síntesis explicativa acerca del funcionamiento de la justicia en Córdoba:

todos los juicios relativos a cuestiones criminales o de índole matrimonial, patrimonial o sucesorias - entre otras - debían ser tramitadas por los alcaldes de primer y segundo voto del cabildo de Córdoba. En caso de que hubiera acontecido un hecho criminal en alguno de los curatos [...] la sumaria debía ser iniciada por el alcalde de la santa hermandad, el juez pedáneo o el comisionado, y una vez concluida, debía ser enviada a los juzgados de Córdoba - junto al "reo" o "rea", si los había - para concluir el juicio (VASSALLO 2007, p. 238).

No sorprende que quien, sondeando otros temas, utilizó como base documental las causas judiciales del Arzobispado de Córdoba (GHIRARDI; VASSALLO 2008) haya omitido aspectos sustanciales de la justicia eclesiástica, ya que es muy poco lo que se conoce acerca de sus formas procesales y su articulación con la justicia secular.

En particular, merecería profundizarse la pesquisa sobre el ambivalente rol de mediación y de expresión del poder político local que suponía el ejercicio de la justicia impartida por los clérigos en ciudades que no fueron sede de tribunales diocesanos, pero que, aun así, tuvieron juzgados eclesiásticos.

De todos modos, Buenos Aires sigue siendo uno de los pocos espacios estudiados desde una perspectiva que contempló el funcionamiento de "las justicias" -militar, eclesiástica y civil - (FRADKIN 2007). Aun así, el tratamiento 
de la jurisdicción eclesiástica se ciñe prácticamente a las últimas tres gestiones borbónicas, posiblemente debido a la mayor abundancia de documentos, ${ }^{5}$ pero, curiosamente, coincidiendo con el período en el cual comienzan las embestidas contra las potestades judiciales de los curas y las quejas sobre la supresión del fuero eclesiástico, que concedía al clero inmunidad frente a la jurisdicción real. Ese es el contexto en el que explotan las doctrinas sobre los recursos de fuerza, que fueron cada vez más requeridos a medida que avanzaba la centuria (LEVAGGI 1995) y, de ahí, la publicación de instrucciones sobre su uso (ACEDO RICO 1794) y la abundancia de los expedientes generados por dichas apelaciones en las audiencias indianas.

Los tramitados ante la Audiencia de Buenos Aires constituyeron la fuente primordial de los trabajos de Silvia Mallo, quien abrió una de las ventanas posibles para asomarse a la justicia eclesiástica en el Río de la Plata. La autora apuntó hacia las actitudes del clero rioplatense en un clima de fuerte disciplinamiento, de reforma de las costumbres (MALLO 2000-2001), y advirtió la recurrencia de los enfrentamientos entre las instituciones clericales tanto como las tensiones entre las jurisdicciones eclesiásticas y reales. Con el objeto de comprobar que ambas administraciones afectaron el comportamiento de los "individuos" e incidieron en determinados "valores" sociales, examinó la utilización de los recursos de fuerza en ese período de cambios. Por eso, no soslayó la existencia de tribunales eclesiásticos y tribunales reales $y$, pese a que su interés estaba focalizado en esos discursos modeladores de las conciencias y prácticas sociales, tales como 220 la conyugalidad, la vida maridable, la conducta de los clérigos y religiosos, vislumbró el rol que le cupo en ese proceso a la administración de la justicia en los tribunales eclesiásticos y a la apelación al derecho canónico (MALLO 1998). Frente a una imagen estereotipada de una administración borbónica pretenciosa de intervenir en todas las cuestiones religiosas, sus artículos exhiben dictámenes diferenciados del tribunal real y distinguen la cautela de los mismos frente a causas que la autora comprendió como "cuestiones internas de la Iglesia"; y, por el contrario, apuntan a una decidida intervención en aquellas otras que relacionaba con "la vida privada de los súbditos laicos" (MALLO 2000-2001, p. 8 ). Condicionada teórica y metodológicamente por los conceptos y categorías analíticas utilizadas - Estado, Iglesia, poder, control social -, como se observa también en otras producciones historiográficas, la de Mallo no inquirió sobre aspectos centrales para comprender el funcionamiento de esos canales judiciales y extrajudiciales habilitados por los jueces eclesiásticos. Tampoco profundizó en el aspecto recursivo de la justicia eclesiástica parroquial de parte de los miembros beneméritos ni de parte de aquellos otros a quienes la legislación indiana asignó la condición de rústico, persona miserable o menor y que eran parte de las comunidades que la autora estudiaba. Aun así, nos lega esa imagen impresionista del vastísimo universo documental que constituyen los recursos de fuerza y por medio del cual es posible indagar una parte de la justicia eclesiástica

${ }^{5}$ En gran medida, la investigación viene condicionada por la desaparición de una gran masa documental en consecuencia del incendio del archivo de la curia en Buenos Aires. 
que es aquella que escapó del propio fuero y fue resistida, cuestionada, por momentos, avasallada, pero coetáneamente buscada por algunos pleiteantes, consentida y protegida por los oficiales reales.

En el tema específico de nuestra búsqueda, los trabajos de María Elena Barral (BARRAL 2003; 2009) siguen marcando los trazos inaugurales y solo excepcionalmente han encontrado diálogo en otros trabajos sobre la región (CITTERIO 2009). Sus aportes sobre la inserción del clero, en calidad de mediador, en esas pequeñas comunidades, a partir del análisis de las funciones judiciales de los párrocos rurales, anticiparon para el Río de la Plata una inquietud que deviene una propuesta en plena vigencia:

Que los párrocos hayan desempeñado las funciones judiciales propias de sus cargos; que además intervinieran informalmente en la resolución de conflictos locales y que estas mediaciones engendraran enfrentamientos con alcaldes y jueces civiles, hacen que el estudio del ejercicio de la justicia eclesiástica cobre relevancia al pensar el tema más amplio de la construcción del poder en estas sociedades (BARRAL 2003, p. 12).

Por último, quiero referir a otro giro de la historiografía americanista que nos acerca una posibilidad de abordar la justicia eclesiástica. A partir de finales de la década de 1980, la teoría de las redes sociales comenzó a utilizarse también para explicar las relaciones de los jueces y su impacto en la administración de justicia (MOUTOUKIAS 2002; AMADORI 2008; DALLA CORTE 2000). La reconstrucción y observación de redes en esta materia supuso un importante revulsivo y, en muchos casos, permitió apreciar cuestiones que hasta ese momento habían pasado inadvertidas. Así, la historia política fue ampliando ese reducido nivel de problematización restringido solo a un número acotado de actores, puesto que se centraba en la órbita de la administración central y de sus instituciones, y que coartaba, así, el conocimiento histórico acerca de las dimensiones sociales y de los múltiples condicionantes de las agencias políticas (AMADORI 2008, p. 11).

Como hemos expresado, en el ámbito de esos tribunales eclesiásticos y en la decisión de los vicarios eclesiásticos residía el poder de evitar, propender y/o consolidar vínculos y relaciones de diversa naturaleza (matrimoniales, filiales, compadrazgo y otros lazos como el de clientelismo, amistad, paisanaje o de negocios) mediante los cuales se canalizaba la construcción de las élites y sus relaciones de subyugación y explotación sin necesitar inexorablemente prebendas o cargo reales. Así, las conexiones familiares que unen linajes, grupos de poder locales, con titulares de los tribunales eclesiásticos parroquiales, diocesanos o arquidiocesanos devienen cuestiones de gran importancia que apenas han sido exploradas. Quienes han trabajado con expedientes judiciales habrán comprobado que por momentos es muy difícil saber las motivaciones de los oficiales de justicia que, ante los mismos delitos, actuaban de formas muy distintas. La apuesta a ese abordaje relacional de las agencias eclesiásticas en el ámbito de la justicia diocesana apunta a esa cuestión. Se sabe de la existencia de tales redes, pero lo que se plantea es tanto un nuevo ámbito de acción como la potencialidad para establecer procedencia estamental de sus 
agentes, frecuencias, intermitencias y duraciones de los flujos relacionales de la misma. Las redes no funcionaban sin tiempo histórico, que, por lo demás, podía ser estrictamente coyuntural, ni tampoco fueron siempre efectivas, pero es viable la reconstrucción de algunos de sus tramos que permitan asignar significados a algunas motivaciones en los fallos de los jueces eclesiásticos independientemente de la efectividad de los mismos.

Desde la historiografía novohispana, Traslosheros ha propuesto que, para el abordaje de esos tribunales, no debiera restringirse exclusivamente al expediente judicial, a la práctica foral ni a la legislación vigente, sino abarcar toda "acción social judicialmente orientada", es decir aquellas acciones que transcurren en un ámbito institucional que dispone de un cuerpo normativo y habilita específicas tramas relacionales, las cuales insuflan capacidad de permanencia, cambio y adaptación a ese cuerpo normativo en el que está incluida la costumbre como fuente de derecho y que, en el período estudiado, está condicionado por una "racionalidad claramente religiosa" (TRASLOSHEROS 2010; 2011).

\section{Conclusiones}

Desde registros de análisis tan distintos se pueden verificar las confluencias entre sociedad, religión, política y justicia. Dos condiciones del ámbito que proponemos indagar son ineludibles: las potestades de algunos eclesiásticos para administrar justicia y la superposición de las jurisdicciones eclesiásticas y civiles.

222 Ofrecimos señales historiográficas que muestran la potencialidad de ese ámbito judicial para completar y complejizar el panorama más amplio de la historia de la justicia en el Río de la Plata. Su estudio tendrá réditos - tanto para operaciones de historia comparada de las experiencias en los diferentes territorios diocesanos, como para una historia integral de la administración de justicia - si atendemos a las directrices que van trazándose en los balances historiográficos sobre lo que, denominado con diferentes expresiones cuestión criminal, justicia penal-, compone dicha área de estudios. Como se sigue del aparato erudito de esta comunicación, hay líneas analíticas que ostentan sólidos resultados, están disponibles y se precian como promisorias para iniciar la tarea que representa la aproximación a fondos documentales judiciales eclesiásticos.

Si bien los pleitos constituyen la expresión práctica de la administración de justicia eclesiástica, los expedientes judiciales no constituyen la totalidad del corpus documental. Como lo han demostrado los historiadores del derecho y aquellos que cultivan la historia social de la justicia, es preciso someter a análisis los documentos relativos a los oficios actuantes en este foro, la bibliografía jurídica y la normativa vigente. El cruce de las diferentes fuentes bajo la luz de esas perspectivas permitirá abrir el espectro de indagación, generalmente circunscrito a la dimensión sociocultural de las materias llevadas a dicha instancia judicial, incorporando la dimensión política que la administración de justicia eclesiástica tuvo en las comunidades referidas. 


\section{Referencias bibliográficas}

ACEDO-RICO, Juan (Conde de la Cañada). Observaciones prácticas sobre los recursos de fuerza. $2^{\text {a }}$ Edición. Madrid: Imprenta de Benito Cano, 1794.

AGÜERO, A. Las penas impuestas por el Divino y Supremo Juez. Religión y justicia secular en Córdoba del Tucumán (Siglos XVII y XVIII). Jahrbuch für Geschichte Lateinamerikas, Köln: Böhlau, no 46, p. 203-230, 2009.

Castigar y perdonar cuando conviene a la República. La justicia penal de Córdoba del Tucumán, siglos XVII y XVIII. Madrid: Centro de Estudios Políticos y Constitucionales, 2008.

AGUIRRE, R. El establecimiento de jueces eclesiásticos en las doctrinas de indios. El arzobispado de México en la primera mitad del siglo XVIII. Historia Crítica, Bogotá, no 36, p. 14-35, julio-diciembre 2008.

AMADORI, Arrigo. Los análisis de redes sociales y el ejercicio del poder: América Hispana. Épocas, USAL, no 2, p. 35-59, 2008.

ANDRÉS-GALLEGO, J. Derecho y justicia en la España y la América prerrevolucionarias. Madrid: Fundación Histórica Tavera, 2000.

ARANCIABIA, J. M.; DELLAFERRERA, N. El Sínodo del obispo Mercadillo: Córdoba, 1700. Teología, no 34, p.101-130, 1979.

ARES QUEIJA, B. El papel de mediadores y la construcción de un discurso sobre la identidad de los mestizos peruanos (siglo XVI). In: ARES QUEIJA, B.; GRUZINSKI, S. (coord.) Entre dos mundos. Fronteras culturales y agentes mediadores. Sevilla: Escuela de Estudios Hispano-Americanos, 1997. p. 37-59.

ASPELL, M. ¿Qué mandas hacer de mí? Córdoba: Mónica Figueroa Editora, $2006 a$.

. Las denuncias por brujería, hechicería, magia y adivinación presentadas ante el Santo Oficio de la Inquisición de Córdoba del Tucumán. Siglo XVIII. Cuadernos de Historia, Córdoba: Instituto de Historia del Derecho y de las Ideas Políticas Roberto I. Peña, no XVI, p. 23-52, 2006b.

El trabajo cotidiano de los Comisarios Inquisitoriales del Tribunal del Santo Oficio de la Inquisición en Córdoba del Tucumán. Siglo XVIII. In: CÓRDOBA, Junta Provincial de Historia de. Córdoba, entre campanas y chimeneas. Córdoba: JPHC, 2007. p. 27-66.

BARRAL, M. E. Fuera y dentro del confesionario. Los párrocos rurales de Buenos Aires como jueces eclesiásticos a fines del período colonial. Quinto Sol, n० 7, p. 11-36, 2003.

. De sotana por la Pampa: religión y sociedad en el Buenos Aires rural tardocolonial. Buenos Aires: Prometeo, 2007.

. Los párrocos como mediadores en las fronteras del mundo colonial. Buenos Aires rural en el siglo XVIII. In: BARRIERA, Darío (coord.). 
Justicias y Fronteras. Estudios sobre historia de la Justicia en el Río de la Plata (Siglos XVI-XIX). Murcia: Editum, 2009. p. 65-117.

BARRIERA, D. La ciudad y las varas: justicia, justicias y jurisdicciones (Ss. XVIXVII). Revista de Historia del Derecho. Buenos Aires: Instituto de Investigaciones de Historia del Derecho, V. XXXI, p. 69-95, 2003.

Justicias, jueces y culturas jurídicas en el siglo XIX rioplatense. Nuevo Mundo Mundos Nuevos. Debates, 2010. Disponible en: http:// nuevomundo.revues.org/59252. Acceso el: 26 de mayo 2010.

- El execrable libro de sus hechos. Cultura jurídica, retórica y deslegitimación de la autoridad en un proceso contra el alcalde del Rosario (1810-1811). Anuario del Instituto de Historia Argentina, FAHCE, UNLP, no 10, 2010. Disponible en: www.memoria.fahce.unlp.edu.ar/art_ revistas/pr.4699/pr.4699.pdf. Acceso el: 8 de mar. 2011.

BARRIERA, D.; DALLA CORTE, G. La ventana indiscreta. La historia y la antropología jurídicas a través de la emoción de sus textos. Prohistoria, Rosario, no 5, p. 11-14, 2001.

BOIXADÓS, R. No ha tenido hijo que más se le parezca así en la cara como en su buen proceder. Una aproximación al problema del mestizaje y la bastardía en La Rioja colonial. Memoria Americana, no 13, 2005.

BRUNO, C. El derecho público de la Iglesia en Indias. Salamanca: Publicaciones del Instituto San Raimundo de Peñafort, 1967.

CANDIOTI, M. Historia y Cuestión Criminal. Notas sobre el despliegue de una curiosidad. In: SOZZO, M. (coord.). Historias de la Cuestión Criminal en la Argentina. Buenos Aires: Ediciones del Puerto, 2009. p. 7-30.

CAULA, E. Jurisdicciones en tensión. Poder patriarcal, legalidad monárquica y libertad eclesiástica en las dispensas matrimoniales del Buenos Aires virreinal. Prohistoria, Rosario, no 5, p.123-142, 2001.

CITTERIO, D. Clero y Justicia en la campaña de Buenos Aires a fines del siglo XVIII. Los casos de los sacerdotes de Chascomús y San Vicente. In: Actas Segundas Jornadas Nacionales de Historia Social. Córdoba: CEH Carlos Segretti -CEHAC_UNLP, 13, 14 y 15 de mayo de 2009. Disponible en: http://www.cehsegreti.com.ar/historia-social-2/mesas ponencias/ MESA 4/Ponencia CiterioDiego.pdf

CLAVERO, B. Delito y pecado. Noción y escala de transgresiones. En TOMÁS; VALIENTE, F. et al. Sexo barroco y otras transgresiones premodernas. Madrid: Alianza, 1990. p. 57-89.

DALLA CORTE, G. La historia del derecho en la Argentina o la Historia Jurídica como proceso. Prohistoria, Rosario, no 3, 1999, p. 133-157.

. La red social frente a la crisis del orden colonial: compensación judicial y vínculos de parentesco entre Buenos Aires y Cataluña. Colonial Latin 
American Historical Review, Alburquerque: Spanish Colonial Research

Center, University of New Mexico, no 9, 2000.

DANWERTH, O. Perfiles de la muerte andina. Ritos funerarios indígenas en concilios y sínodos del Perú colonial (1549-1684). In: SCHMIDT-RIESE, Roland (ed.). Catequesis y derecho en la América colonial. Fronteras borrosas. Frankfurt-Madrid, Verveurt 2010. p. 41-71.

DELLAFERRERA, N.; MARTINI, M. Temática de las constituciones sinodales indianas (s. XVI - XVIII). Arquidiócesis de la Plata. Buenos Aires: Instituto de Investigaciones de Historia del Derecho, 2002.

DELLAFERRERA, N. Un caso de nulidad matrimonial en el siglo XVIII. Teología, Buenos Aires: Pontificia Universidad Católica Argentina, no 57, p. 97$110,1991$.

- La justicia penal eclesiástica en Córdoba del Tucumán durante el siglo XVIII. In: BARRIOS PINTADO, F. Derecho y administración pública en las Indias hispánicas: actas del XII Congreso Internacional de Historia del Derecho Indiano. Toledo, 19 a 21 de octubre de 1998. V. 1, Toledo: Cortes de Castilla-La Mancha - Universidad de Castilla-La Mancha 2002. p. 405-428.

- Fuentes del derecho canónico indiano en los siglos XVI-XVII: Ios confesonarios. Cuadernos de historia, Instituto del Derecho y de las Ideas Políticas, no 14, p. 49-66, 2004.

. Apuntes para la Historia del Derecho Canónico Indiano. Cuadernos de Historia, V. XVI, 2006.

. El sínodo de Buenos Aires y la lengua de la predicación. Revista de Historia del Derecho, Buenos Aires: INHIDE, no 36, p. 325-363, 2008.

DI STEFANO, R. EI púlpito y la plaza. Clero, sociedad y política de la Monarquía católica a la República rosista. Buenos Aires: Siglo XXI, 2004.

DUVE, T. Algunas observaciones acerca del modus operandi y la prudencia del juez en el derecho canónico indiano. Revista de Historia del Derecho, Buenos Aires: INHIDE, no 35, p. 195-226, 2007.

- La jurisdicción eclesiástica sobre los indígenas y el trasfondo del Derecho Canónico universal. In: ZABALLA BEASCOECHEA, A. (ed.) Los indios el Derecho Canónico y la justicia eclesiástica en la América virreinal. Madrid: Iberoamericana, 2011. p. 29-44.

FARBERMAN, J. Las salamancas de Lorenza: magia, hechicería y curanderismo en el Tucumán colonial. Buenos Aires: Siglo XXI, 2005.

FARGE, A. La atracción del archivo. Valencia: Institucio Alfons El Magnanim, 1991. FERREYRA, M. C. Matrimonios de españoles con esclavos durante el siglo XVIII en Córdoba. In: GHIRARDI, M. (comp.). Cuestiones de familia a través de las fuentes. Córdoba: UNC, 2005. p. 91-139. 
FEITLER, B. Poder Episcopal e Inquisição no Brasil: o Juízo Eclesiástico da Bahia nos tempos de D. Sebastião Monteiro da Vide. En: FLEITER, B.; SALES SOUZA, E. (org.). A Igreja no Brasil. Normas e Práticas durante a Vigência das Constituições Primeiras do Arcebispado da Bahia. São Paulo: UNIFESP, 2011. p. 85-110.

FOGELMAN, P. Los enemigos de la fe en el Río de la Plata colonial. En: FORTE, R.; SILVA PRADA, N. (coord.). Cultura política en América. Variaciones regionales y temporales. México: Universidad Autónoma Metropolitana, Unidad Iztapalapa, GEHPA, 2006. p. 45-69.

FOUCAULT, M. La vida de los hombres infames. La Plata: Altamira, 1996.

FRADKIN, R. (comp.). EI poder y la vara: estudios sobre la justicia y la construcción del Estado en el Buenos Aires rural. Buenos Aires: Prometeo, 2007.

GARAVAGLiA, J. C. San Antonio de Areco, 1680-1880: un pueblo de la campaña, del Antiguo Régimen a la modernidad argentina. Prohistoria, Rosario, 2009.

GARCÍA BELSUNCE, C. Los clérigos como agentes de la Administración en el Derecho Indiano y Patrio. In: Una ventana al pasado. Rosario: Instituto de Historia Política Argentina, 1994. p. 17-42.

GARRIGA, C. Sobre el gobierno de la justicia en Indias (siglo XVI-XVII). Revista de Historia del Derecho, Buenos Aires: INHIDE, no 34, p. 67-160, 2006.

GHIRARDI, M.; VASSALLO, J. El encierro femenino como práctica. Notas para el ejemplo de Córdoba, Argentina, en el contexto de Iberoamérica en los siglos XVIII y XIX. III Congreso de la Asociación Latinoamericana de Población. Córdoba: ALAP, 2008. Disponible en: http://www.alapop. org. Acceso el: 11 de abr. 2010.

GHIRARDI, M. Historias íntimas de hombres y mujeres en el orden finicolonial cordobés. Colonial Latin American Historical Review, México: Albuquerque, Spanish Colonial Research Center, University of New Mexico, V. 12 , no 4, p. 373-414, Fall 2003.

- Matrimonios y familias en Córdoba, 1700-1850: prácticas y representaciones. Córdoba: UNC - Ferreyra Editor, 2004.

GUIBOVICH PÉREZ, P. Censura, libros e inquisición en el Perú colonial, 15701754. Sevilla: CSIC, Universidad de Sevilla, Diputación de Sevilla, 2003.

KLUGER, V. Disciplinamiento familiar y social en el Río de la Plata, Tucumán y Cuyo. Amancebados, casados ausentes e hijos fugitivos en la mira de los Bandos de buen Gobierno. Revista de Historia del Derecho, Buenos Aires: INHIDE, no 33, p. 131-158, 2005.

LARA CISNEROS, G. La justicia eclesiástica ordinaria y los indios en la Nueva España borbónica: balance historiográfico y prospección. In: TRASLOSHEROS, 
J.; ZABALLA BEASCOECHEA, A. (coord.) Los indios ante los foros de justicia religiosa en la Hispanoamérica virreinal. México: Universidad Nacional Autónoma de México, Instituto de Investigaciones Históricas, 2010. p. 127-156.

LAVALLÉ, B. (dir.). Transgressions et stratégies du métissage en Amérique coloniale. Paris: Centre de recherche sur l'Amérique espagnole coloniale, Presses Sorbonne Nouvelle, 1999.

LAVRIN, A. La mujer en la sociedad colonial hispanoamericana. In: BETHELL, L. Historia de América Latina. Tomo IV. Barcelona: Cambridge University Press, 1993. p. 109-137.

LEVAGGI, A. Dalmacio Vélez Sársfield y el derecho eclesiástico. Buenos Aires: Perrot, 1969.

. Los recursos de fuerza en el derecho indiano. Con especial referencia

a las doctrinas del oidor Manuel Silvestre Martínez y del obispo Manuel Azamor y Ramírez. Revista de Historia del Derecho, Buenos Aires: INHIDE, no 31, p. 75-126, 1995.

LÓPEZ, G. Juicios de disenso por diversidad étnica y por diferencia de linaje en Mendoza a fines del siglo XVIII: Francisco Martínez de Virgala contra Solana Riveros y los Videla. In: SIEGRIST, Nora; GHIRARDI, Mónica (coords.). Mestizaje, sangre y matrimonio en territorios de la actual argentina y Uruguay: siglos XVII-XX. Buenos Aires: Dunken, 2008. p. 101-124.

MALLO, S. Justicia, divorcio, alimentos y malos tratos en el Río de la Plata, 17661857. Investigaciones y Ensayos, Buenos Aires: Academia Nacional de la Historia, no 42, p. 373-400, 1992.

. Justicia Eclesiástica y Justicia Real. Los recursos de fuerza en el Río de la Plata. 1785-1857. Trabajos y comunicaciones (2a Época), La Plata: FAHCE, UNLP, no 25, p. 267-292, 1998.

. Iglesia, valores cristianos y comportamientos: el Río de la Plata a fines del período colonial. Trabajos y comunicaciones (2a Época), La Plata: FAHCE, UNLP, no 26-27, p. 93-113, 2000-2001.

. La sociedad rioplatense ante la justicia. La transición del siglo XVIII al XIX. La Plata: Asociación de Amigos del Archivo Histórico de la Provincia de Buenos Aires, 2004.

MARTÍNEZ DE SÁNCHEZ, A. M. Las consuetas de las catedrales de Santiago del Estero y de Córdoba en los siglos XVII y XVIII. In: GONZÁLEZ VALE, L. (coord.). Actas de Derecho Indiano, XIII Congreso Instituto Internacional de Historia de Derecho Indiano, Tomo II. San Juan de Puerto Rico: Academia Portorriqueña de la Historia, 2003. p. 41-68.

MARTINI, M. La legislación canónica y real en torno a los indios y la muerte en Hispanoamérica colonial. Memoria del X Congreso del Instituto Internacional de Historia del Derecho Indiano. México: UNAM, 1995. 
MENDONÇA, P. G. O tribunal episcopal do obispado do Maranhão: dinâmica processual e jurisdição eclesiástica no século XVIII. In: FLEITER, B.; SALES SOUZA, E. (org.). A igreja no Brasil. Normas e Práticas durante a Vigência das Constituições Primeiras do Arcebispado da Bahia. São Paulo: UNIFESP, 2011. p. 481-506.

MOLINA, R. La familia porteña en los siglos XVII y XVIII. Historia de los divorcios en el periodo hispano. Buenos Aires: Fuentes históricas y genealógicas argentinas, 1991.

MORICONI, M. El curato de naturales en Santa Fe del Río de la Plata. Siglos XVIIXVIII. Hispania Sacra, Madrid: CSIC, LXIII, no 128, p. 423-432, 2011.

MOUTOUKIAS, Z. Las formas complejas de la acción política: justicia corporativa, faccionalismo y redes sociales (Buenos Aires, 1750-1760). Jahrbuch für Geschichte von Staat, Wirtschaft und Gesellschaft Lateinamerikas, Köln: Böhlau, no 39, p. 69-102, 2002.

PALACIO, J. M.; CANDIOTI, M. Justicia, política y derechos en América Latina. Apuntes para un diálogo interdisciplinario. In: PALACIO, J. M.; CANDIOTI, M. (comp.). Justicia, política y derechos en América Latina. Buenos Aires: Prometeo, 2007. p. 11-24.

PEÑA, G. Las ordenanzas capitulares de la provincia dominicana de San Agustín (República Argentina): 1724-1824. In: GONZÁLEZ VALE, L. (coord.) Actas

228 y estudios de Derecho Indiano. XIII Congreso Instituto Internacional de Historia de Derecho Indiano, Tomo I. San Juan de Puerto Rico: Academia Portorriqueña de la Historia, 2003. p. 119-124.

RÍPODAS ARDANAZ, D. El matrimonio en Indias. Realidad social y regulación jurídica. Buenos Aires: Fundación para la Educación, la Ciencia y la Cultura, 1977.

SUÁREZ, T. Sexualidad y Sociedad en la Colonia Marginal. Santa Fe 16801780. Tesis doctoral. La Plata: UNLP, 1993.

TAU ANZOÁTEGUI, V. Casuismo y sistema. Indagación histórica sobre el espíritu del Derecho Indiano. Buenos Aires: IHD, 1992.

TRASLOSHEROS, J. Iglesia, justicia y sociedad en la Nueva España. La audiencia del arzobispado de México. México: Universidad Iberoamericana-Porrúa, 2004.

Invitación a la historia judicial. Los tribunales en materia religiosa y los indios de la Nueva España: problemas, objeto de estudio y fuentes. In: MARTÍNEZ LÓPEZ-CANO, M. P. La Iglesia en Nueva España. Problemas y perspectivas de investigación. México: UNAM, 2010a. p. 129-149.

Los indios, la Inquisición y los tribunales eclesiásticos ordinarios en Nueva España. Definición jurisdiccional y justo proceso, 1571-c.1750. In: TRASLOSHEROS, J.; ZABALLA BEASCOECHEA, A. (coord.), Los indios 
ante los foros de justicia religiosa en la Hispanoamérica virreinal. México: UNAM, 2010b. p. 17-46.

VASSALLO, J. Delincuentes y pecadoras en la Córdoba tardo colonial. Anuario de Estudios Americanos, Sevilla, no 63, p. 97-116, 2006.

VÉLEZ SARSFIELD, D. Derecho público eclesiástico. Relaciones del Estado con la iglesia en la antigua América española. Buenos Aires: Imprenta de La Tribuna, 1871.

ZABALLA BEASCOECHEA, A. (edit.) Los indios el Derecho Canónico y la justicia eclesiástica en la América virreinal. Madrid: Iberoamericana, 2011. 